\title{
Accuracy of current profile measurements: Effect of tropical and midlatitude internal waves
}

\author{
Uwe Send \\ Institut für Meereskunde, Kiel, Germany
}

\begin{abstract}
The effect of midlatitude and tropical internal wave variability on current profile measurements is investigated and quantified to yield practical error estimates. First, a data set of Pegasus current profiles from the tropical Atlantic $\left(6^{\circ} \mathrm{S}\right.$ to $\left.6^{\circ} \mathrm{N}\right)$ is analyzed for their rms down/up differences, which are compared with predictions from Garrett-Munk type internal wave theory and with statistics derived from current meter moorings in the same region. The agreement in terms of amplitudes and vertical distribution proves that most of those differences are due to internal waves and not instrumental errors. Nonetheless, this is the noise of the measurements, if lowfrequency motions are sought, and the errors can thus be quantified using the same internal wave theories. At midlatitudes the error variance is the usual $44(N / 3 \mathrm{cph})$ $\mathrm{cm}^{2} / \mathrm{s}^{2}$ with some latitude dependence, and the effect of averaging in the vertical or summing several profiles (e.g., up and down) is estimated. The same is done for equatorial situations, where construction of a crude equatorial frequency spectrum for internal waves yields $77(N / 3 \mathrm{cph}) \mathrm{cm}^{2} / \mathrm{s}^{2}$ for the error variance. Again, error reduction due to averaging is estimated.
\end{abstract}

\section{Introduction}

A variety of approaches exists to obtain vertical profiles of currents in the ocean. Current meter moorings, while yielding very useful time series of such profiles, are very expensive to prepare and maintain and are thus only realizable at few locations. Geostrophic current profiles calculated from hydrographic data, on the other hand, can be obtained for many stations during one cruise but are only an indirect measurement, involving an approximation that breaks down, for example, near the equator. They also require knowledge of an absolute reference level for the currents. Current profile measurements with instruments that are free falling or lowered on a cable have the advantage of allowing good spatial coverage (often identical to hydrographic conductivity-temperature-depth (CTD) stations) while being a direct measurement. This virtue is offset by the fact that temporal information is not available, making it difficult to judge how "representative" a measured profile is, given the presence of variability on time-scales that are considered noise. This problem is addressed here, from the standpoint of wanting to measure low-frequency variability that is contaminated by internal wave type motions, with the aim of providing practical estimates of the induced errors.

The recently most widely used current profiler is the free-falling "Pegasus" probe [Spain et al., 1981], whose motion through the current shear is tracked with acoustic transponders deployed on the ocean floor. Other promising techniques exist like lowering an ADCP together with the CTD instrument [Firing and Hacker, 1992; Fischer and Visbeck, 1993]. A very extensive set of equatorial Pegasus data from the Pacific has been published by Firing [1987], who also discussed some of the processing techniques and

Copyright 1994 by the American Geophysical Union.

Paper number $94 \mathrm{JC} 01402$.

0148-0227/94/94JC-01402\$05.00 errors. We now have 2 years of experience with the Pegasus profiler, and a striking observation has been the large differences that are often found between the profiles during the descent and the ascent of the probe. They can differ by as much as $5 \mathrm{~cm} / \mathrm{s}$ in the deepwater column and by more than 15 $\mathrm{cm} / \mathrm{s}$ in the surface layers (at least in the tropical ocean). Theoretical error estimates based on the accuracy of the acoustic travel time, of the transponder location, of the sound speed etc., generally give estimates an order of magnitude smaller than those down/up differences (U. Send et al., Aspects of acoustic transponder surveys and acoustic navigation, submitted to Journal of Atmospheric and Oceanic Technology, 1994; hereafter referred to as U. Send et al., submitted manuscript, 1994]. Nonetheless, these system-inherent errors are usually quoted as the accuracy of the measurement since they are easily quantifiable. The down/up differences are rarely shown in published studies; instead the two profiles are either averaged together or one of them is deemed less accurate and is discarded (usually the up profile, since the probe is expected to have a more stable attitude during descent).

This study will first investigate how much of the observed down/up differences in current profiles can be attributed to natural variability in the ocean. The result will then allow an estimate of the absolute error induced by that variability.

\section{Data Base}

A total of 40 Pegasus profiles from two Meteor expedition in the tropical Atlantic form the basis of this analysis, 1 from Meteor cruise M14, and 21 from cruise M16, listed Table 1. Simultaneous with each cast, a CTD profile w routinely taken, so that the buoyancy frequency $(N)$ prof at each station could be calculated. Figure 1 shows t average buoyancy frequency for all M14 and all M16 Pegas stations, together with its standard deviation. These will used later to calculate the internal wave statistics. 
Table 1. Available Pegasus Stations

\begin{tabular}{|c|c|c|c|c|c|}
\hline $\begin{array}{l}\text { Pro- } \\
\text { file }\end{array}$ & Date & Latitude & Longitude & $\begin{array}{c}\text { Profile } \\
\text { Depth, } \\
\text { m }\end{array}$ & $\begin{array}{c}\text { Water } \\
\text { Depth, } \\
\text { m }\end{array}$ \\
\hline \multicolumn{6}{|c|}{ Cruise $M 14$} \\
\hline 1 & Oct. 6,1990 & $6^{\circ} 38.8^{\prime} \mathrm{N}$ & $44^{\circ} 02.6^{\prime} \mathrm{W}$ & 1930 & 4600 \\
\hline 2 & Oct. 7,1990 & $5^{\circ} 13.8^{\prime} \mathrm{N}$ & $44^{\circ} 04.0^{\prime} \mathrm{W}$ & 1900 & 3300 \\
\hline 3 & Oct. 7, 1990 & $4^{\circ} 12.6^{\prime} \mathrm{N}$ & $44^{\circ} 02.0^{\prime} \mathrm{W}$ & 2200 & 4200 \\
\hline 4 & Oct. 8,1990 & $3^{\circ} 14.8^{\prime} \mathrm{N}$ & $44^{\circ} 02.2^{\prime} \mathrm{W}$ & 4200 & 4200 \\
\hline 5 & Oct. 10,1990 & $0^{\circ} 07.8^{\prime} \mathrm{N}$ & $44^{\circ} 21.4^{\prime} \mathrm{W}$ & 930 & 1200 \\
\hline 6 & Oct. 11,1990 & $0^{\circ} 51.7^{\prime} \mathrm{N}$ & $44^{\circ} 01.2^{\prime} \mathrm{W}$ & 4000 & 4000 \\
\hline 7 & Oct. 12,1990 & $0^{\circ} 16.1^{\prime} \mathrm{N}$ & $44^{\circ} 19.8^{\prime} \mathrm{W}$ & 2300 & 3000 \\
\hline 8 & Oct. 13,1990 & $1^{\circ} 57.7^{\prime} \mathrm{N}$ & $44^{\circ} 01.2^{\prime} \mathrm{W}$ & 900 & 4100 \\
\hline 9 & Oct. 13,1990 & $1^{\circ} 57.3^{\prime} \mathrm{N}$ & $44^{\circ} 01.3^{\prime} \mathrm{W}$ & 4100 & 4100 \\
\hline 10 & Oct. 17,1990 & $0^{\circ} 01.7^{\prime} \mathrm{S}$ & $35^{\circ} 00.0^{\prime} \mathrm{W}$ & 4500 & 4500 \\
\hline 11 & Oct. 18,1990 & $0^{\circ} 42.6^{\prime} \mathrm{S}$ & $35^{\circ} 00.0^{\prime} \mathrm{W}$ & 4450 & 4450 \\
\hline 12 & Oct. 18,1990 & $1^{\circ} 28.5^{\prime} \mathrm{S}$ & $35^{\circ} 00.0^{\prime} \mathrm{W}$ & 4250 & 4250 \\
\hline 13 & Oct. 19,1990 & $2^{\circ} 17.5^{\prime} \mathrm{S}$ & $34^{\circ} 59.9^{\prime} \mathrm{W}$ & 4000 & 4000 \\
\hline 14 & Oct. 20,1990 & $3^{\circ} 06.5^{\prime} \mathrm{S}$ & $34^{\circ} 53.3^{\prime} \mathrm{W}$ & 3800 & 3800 \\
\hline 15 & Oct. 22,1990 & $5^{\circ} 38.8^{\prime} \mathrm{S}$ & $34^{\circ} 54.5^{\prime} \mathrm{W}$ & 900 & 1000 \\
\hline 16 & Oct. 22,1990 & $5^{\circ} 35.2^{\prime} \mathrm{S}$ & $34^{\circ} 36.1^{\prime} \mathrm{W}$ & 3350 & 3350 \\
\hline 17 & Oct. 23, 1990 & $5^{\circ} 39.5^{\prime} \mathrm{S}$ & $34^{\circ} 56.0^{\prime} \mathrm{W}$ & 400 & 700 \\
\hline 18 & Oct. 23,1990 & $5^{\circ} 32.0^{\prime} \mathrm{S}$ & $34^{\circ} 01.7^{\prime} \mathrm{W}$ & 4200 & 4200 \\
\hline 19 & Oct. 25,1990 & $5^{\circ} 20.1^{\prime} \mathrm{S}$ & $32^{\circ} 32.3^{\prime} \mathrm{W}$ & 4600 & 4600 \\
\hline \multicolumn{6}{|c|}{ Cruise MI6 } \\
\hline 1 & May 24, 1991 & $0^{\circ} 08.4^{\prime} \mathrm{N}$ & $44^{\circ} 22.0^{\prime} \mathrm{W}$ & 1000 & 1100 \\
\hline 2 & May 24,1991 & $0^{\circ} 08.2^{\prime} \mathrm{N}$ & $44^{\circ} 21.9^{\prime} \mathrm{W}$ & 1000 & 1100 \\
\hline 3 & May 25,1991 & $0^{\circ} 16.0^{\prime} \mathrm{N}$ & $44^{\circ} 19.7^{\prime} \mathrm{W}$ & 2750 & 3000 \\
\hline 4 & May 25,1991 & $0^{\circ} 52.1^{\prime} \mathrm{N}$ & $44^{\circ} 01.4^{\prime} \mathrm{W}$ & 4000 & 4000 \\
\hline 5 & May 26,1991 & $1^{\circ} 57.7^{\prime} \mathrm{N}$ & $44^{\circ} 01.5^{\prime} \mathrm{W}$ & 4100 & 4100 \\
\hline 6 & May 26,1991 & $3^{\circ} 14.0^{\prime} \mathrm{N}$ & $44^{\circ} 02.1^{\prime} \mathrm{W}$ & 4200 & 4200 \\
\hline 7 & May 27,1991 & $4^{\circ} 12.1^{\prime} \mathrm{N}$ & $44^{\circ} 02.3^{\prime} \mathrm{W}$ & 4200 & 4200 \\
\hline 8 & May 31,1991 & $0^{\circ} 41.8^{\prime} \mathrm{N}$ & $35^{\circ} 00.1^{\prime} \mathrm{W}$ & 3700 & 4500 \\
\hline 9 & May 31,1991 & $0^{\circ} 01.7^{\prime} \mathrm{S}$ & $34^{\circ} 59.7^{\prime} \mathrm{W}$ & 4500 & 4500 \\
\hline 10 & June 1, 1991 & $0^{\circ} 46.8^{\prime} \mathrm{S}$ & $34^{\circ} 59.9^{\prime} \mathrm{W}$ & 4400 & 4400 \\
\hline 11 & June 2, 1991 & $1^{\circ} 28.5^{\prime} \mathrm{S}$ & $35^{\circ} 00.0^{\prime} \mathrm{W}$ & 4300 & 4300 \\
\hline 12 & June 2, 1991 & $1^{\circ} 33.0^{\prime} \mathrm{S}$ & $34^{\circ} 59.9^{\prime} \mathrm{W}$ & 4000 & 4200 \\
\hline 13 & June 3, 1991 & $2^{\circ} 20.3^{\prime} \mathrm{S}$ & $34^{\circ} 59.8^{\prime} \mathrm{W}$ & 3950 & 3950 \\
\hline 14 & June 3, 1991 & $3^{\circ} 09.8^{\prime} \mathrm{S}$ & $34^{\circ} 53.0^{\prime} \mathrm{W}$ & 3800 & 3800 \\
\hline 15 & June 5, 1991 & $5^{\circ} 38.6^{\prime} S$ & $34^{\circ} 54.4^{\prime} \mathrm{W}$ & 800 & 1100 \\
\hline 16 & June 5,1991 & $5^{\circ} 35.1^{\prime} \mathrm{S}$ & $34^{\circ} 39.2^{\prime} \mathrm{W}$ & 3200 & 3200 \\
\hline 17 & June 6,1991 & $5^{\circ} 32.9^{\prime} \mathrm{S}$ & $34^{\circ} 24.0^{\prime} \mathrm{W}$ & 3750 & 3750 \\
\hline 18 & June 6,1991 & $5^{\circ} 32.1^{\prime} \mathrm{S}$ & $34^{\circ} 02.0^{\prime} \mathrm{W}$ & 4200 & 4200 \\
\hline 19 & June 7,1991 & $5^{\circ} 25.7^{\prime} \mathrm{S}$ & $33^{\circ} 15.7^{\prime} \mathrm{W}$ & 4450 & 4450 \\
\hline 20 & June 8, 1991 & $5^{\circ} 20.0^{\prime} \mathrm{S}$ & $32^{\circ} 32.7^{\prime} \mathrm{W}$ & 4550 & 4600 \\
\hline 21 & June 9, 1991 & $0^{\circ} 00.2^{\prime} \mathrm{N}$ & $30^{\circ} 21.8^{\prime} \mathrm{W}$ & 2000 & 4350 \\
\hline
\end{tabular}

For all Pegasus profiles of horizontal currents, the down/up casts were each interpolated onto the same $10-\mathrm{m}$ grid after low-pass filtering with an 80 -m wavelength cutoff, thus preserving features larger than about $40 \mathrm{~m}$. The filtering removes small-scale instrument noise of $2-3 \mathrm{~cm} / \mathrm{s} \mathrm{rms} \mathrm{size}$ which is rather constant over the water column and which mainly comes from point-to-point noise (8-m sampling interval) due to the derivative that is taken from position measurements in the processing. To remove that part of the differences that is due to only a vertical misalignment in the vertical of the down/up profiles (pressure sensor drift), a shift of up to $20 \mathrm{~m}$ (maximum pressure error) was allowed for consecutive $400-\mathrm{m}$ segments of the profiles to minimize the rms difference over each segment. Two typical profiles are shown in Figure 2, where in each case the filtered up/down profiles are plotted and next to it the up/down differences with and without the $20-\mathrm{m}$ shift. Usually, the shift only makes a difference in regions of strong vertical gradients, and in the final rms plots of Figure 3 the changes due to the shift are negligible.
The down/up differences (after filtering and shifting) for each profile were used to calculate the rms difference at each $10-\mathrm{m}$ level formed over all M14 and over all M16 stations which had data at that depth. The resulting profile of rms down/up differences is plotted in Figures $3 a$ and $3 b$, respectively (solid curve), for the subset of stations that were approximately $4000 \mathrm{~m}$ deep $( \pm 600 \mathrm{~m})$. This selection of deep stations is necessary for subsequent quantitative analyses. Including instead all stations, the corresponding plot differs noticeably only for the upper $700 \mathrm{~m}$ of the M14 profile shown. The dashed curve in Figure 3 shows the down/up differences which result if in each Pegasus cast a $400-\mathrm{m}$ average of the differences is taken before forming the rms over all casts. This is an attempt to remove short-scale errors (e.g., due occasional "tumbling" or "spiralling" motion of the probe with $\sim 120-150 \mathrm{~m}$ wavelength), and at the same time this gives down/up differences that are more relevant for estimates of the depth-integrated transport over some layer. As discussed in section 3, this averaging does not remove significant internal wave energy below about $500 \mathrm{~m}$ depth. Therefore the dashed curve is the more relevant quantity to compare with the predictions in Figure 3 below this level, while above (where due to larger currents the instrument noise has a smaller relative contribution) the solid curve should be used.
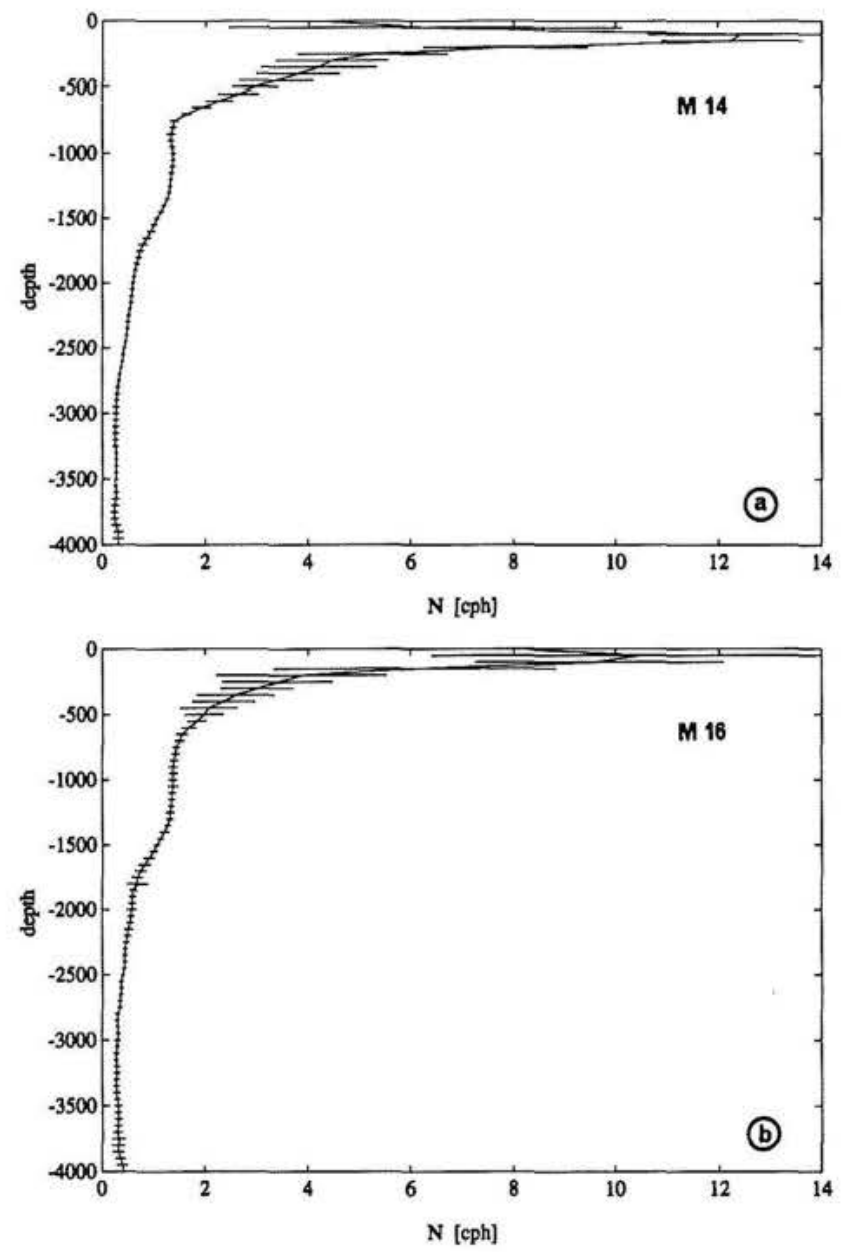

Figure 1. (a) Average M14 and (b) M16 buoyancy frequency profiles, with rms scatter. 
There were some technical differences between the M14 and M16 profiles, which is the reason for plotting and analyzing them separately. During M14 the Pegasus was equipped with factory-supplied fins to make it rotate during descent and ascent for a more stable attitude and vertical motion. During M16 the fins were replaced by a "Hula skirt" of approximately $1-\mathrm{m}$-long strings around the top and bottom of the instrument in order to improve the streaming properties. With that, the vertical speed increased from typically 45 to $60 \mathrm{~cm} / \mathrm{s}$, but frequently, the instrument exhibited shortperiod tumbling motions. These account for the increased level of raw rms down/up differences during M16 (solid curve) relative to the 400-m averages (dashed curve) which largely remove this effect. The absolute level of down/up differences is somewhat lower during M16, and this is believed to be due to the shorter profile duration at the higher drop rates (see below).

Note that all rms currents and differences used in this study refer to the vector magnitude and difference of the current components. Thus the rms values for individual current components would be smaller by a factor of $2^{1 / 2}$ if the currents were isotropic.

\section{Predictions From Internal Wave Spectra}

Given the frequency spectrum $S_{\mathrm{uu}}$ of the horizontal current fluctuations at a point, their covariance function $\mathrm{Cov}_{\mathrm{uu}}$
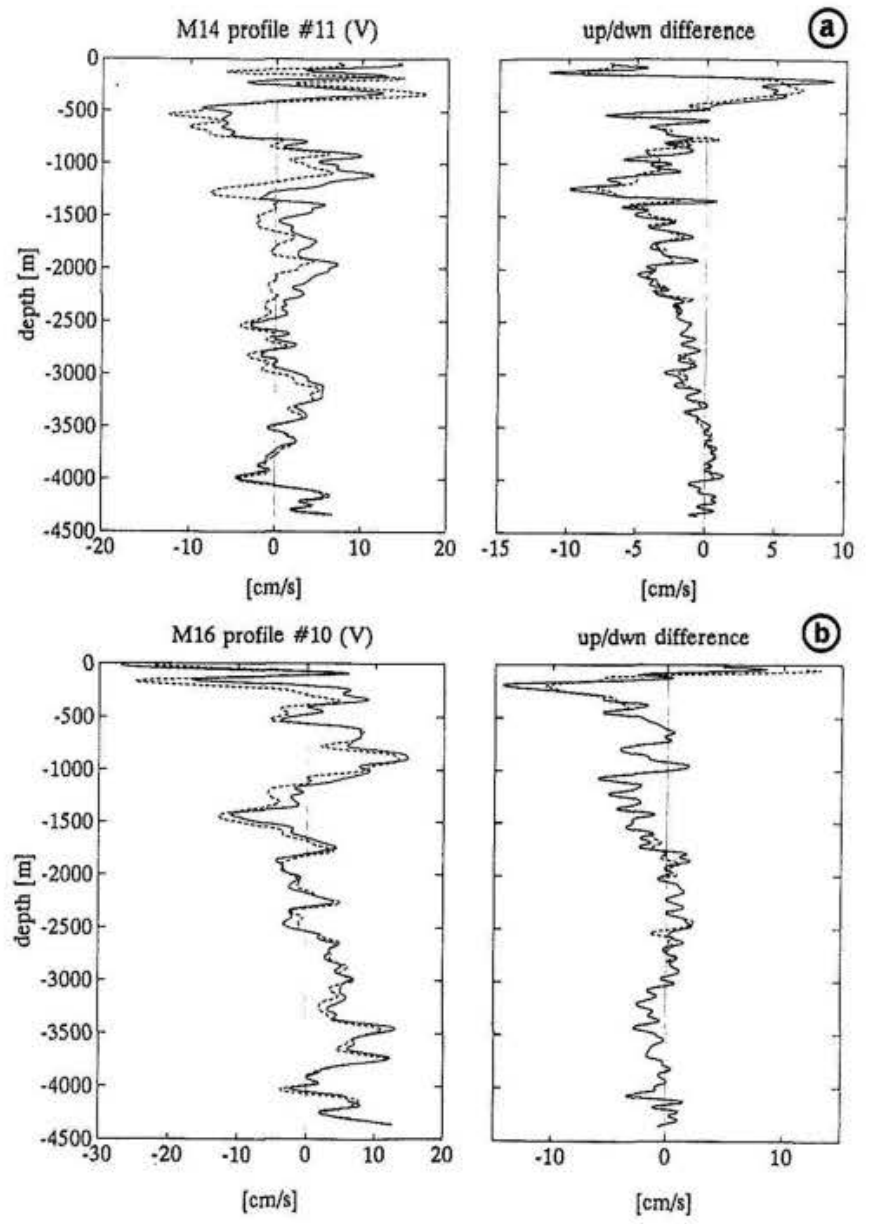

Figure 2. (a) One M14 and (b) one M16 profile showing (left) typical up/down profiles and (right) their difference with (solid) and without (dashed) the up to 20 -m shifting.
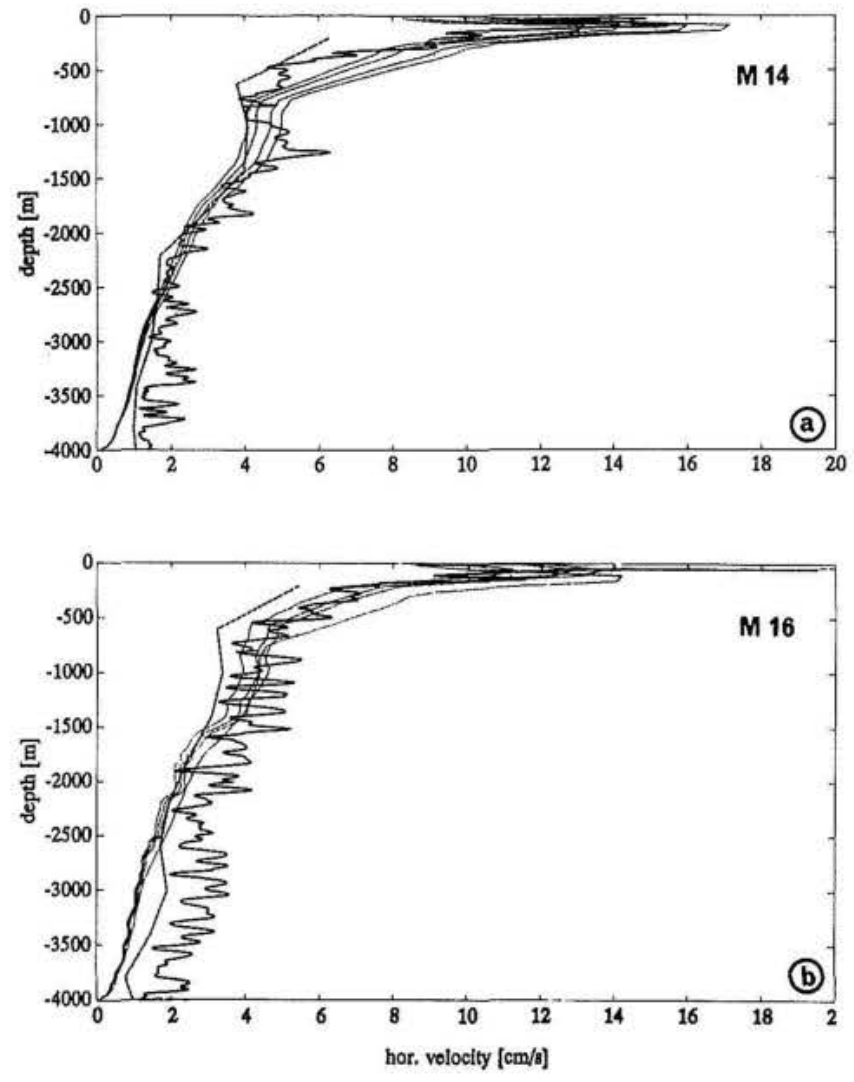

Figure 3. Solid curve is rms difference between deep down/up profiles of horizontal velocity, taken over all (a) M14 and (b) M16 Pegasus stations. Dashed curve is 400-m averages taken in each profile before forming the rms. Dotted curves are predictions with "truncated" and "equatorial" (see text) Garrett-Munk spectrum for various lowfrequency cutoffs.

is given by the Fourier transform of $S_{\mathrm{uu}}$. Thus the structure function can be obtained as

$$
F_{\mathrm{uu}}(t)=\left\langle|\mathbf{u}(0)-\mathbf{u}(t)|^{2}\right\rangle=2\left[\operatorname{Var}_{\mathbf{u}}-\operatorname{Cov}_{\mathbf{u u}}(t)\right]
$$

describing the mean square difference between velocities at the same point separated by a time interval $t$. This relation is correct regardless of $\mathbf{u}$ containing a nonzero mean or not, since such a mean would cancel out in $\mathbf{u}(0)-\mathbf{u}(t)$.

A "standard" Pegasus cast was defined as a 4000-m-deep cast with an equal descent/ascent rate of $0.45 \mathrm{~m} / \mathrm{s}$ for M14 and $0.6 \mathrm{~m} / \mathrm{s}$ for M16, which is within about $5 \%$ of the actual speeds. This allows to estimate the typical time lag between the down/up current values at depth $z$ as

$$
\Delta t(z)=(4000 \mathrm{~m}-z) * 2 / \text { drop rate. }
$$

Knowledge of $S_{\mathrm{uu}}$ at each depth thus allows to estimate the rms difference of the corresponding currents seen during the down/up casts with a Pegasus profiler as $\left\{F_{\mathrm{uu}}[\Delta t(z)]\right\}^{1 / 2}$.

At sufficient distance from the equator, the Garrett-Munk form for the internal wave frequency spectrum can be used:

$$
S_{\mathrm{uu}}=2 \pi^{-1} E b^{2} N_{0} N f_{30^{\circ} \omega} \omega^{-2} B(\omega)
$$

where the factor 


$$
B(\omega)=\frac{\omega^{2}+f^{2}}{\omega\left(\omega^{2}-f^{2}\right)^{1 / 2}}
$$

describes the inertial peak and asymptotes to 1 at higher frequencies, $E=6.3 \times 10^{-5}, b=1.3 \mathrm{~km}, N_{0}=3 \mathrm{cph}$, and $N$ is the buoyancy frequency at the depth considered [Munk, 1981]. Note that in (3) the constant $f_{30^{\circ}}=f\left(30^{\circ} \mathrm{N}\right)$ keeps the spectral level independent of latitude, while in the original formulation of Garrett and Munk [1975] (hereafter referred to as GM75) a latitude dependent factor $f$ was used (keeping the total variance a constant). This modification has been suggested in 14 footnote of Munk [1981, p. 285] and is even consistent with our equatorial spectra where above the tidal frequency a spectral level similar to (3) is found (see below).

In the tropics, where the above Pegasus profiles were collected, the inertial peak disappears in the internal wave spectra, and the spectrum extends to very low frequencies, since $f \rightarrow 0$ and due to the presence of low-frequency equatorially trapped internal waves [e.g., Wunsch and Webb, 1979; Eriksen, 1980]. As an approximation to start with therefore, the form (3) will be used with $B(\omega)=1$. This spectrum cannot be taken to $f=0$, since infinite variance would result. Therefore various low-frequency cutoffs were tried corresponding to $f\left(40^{\circ}\right), f\left(5^{\circ}\right), f\left(1^{\circ}\right)$. These spectra will be referred to as the "truncated Garrett-Munk (GM)" spectrum (TGM), with various cutoffs. In addition, a very crude adjustment of the GM spectral shape to equatorial spectra, presented in section 7 , is used, designated as the "equatorial Garrett-Munk" spectrum (EGM).

Using these spectra for the structure function, relations (1)-(2) were applied to predict the $\mathrm{rms}$ down/up velocity differences in the Pegasus profiles. The resulting curves are included in Figure 3. They are different for M14 and M16 since the respective average buoyancy frequency profiles and drop rates were used. For all attempted models, the agreement with the filtered observations is good, with a maximum difference by a factor of 2 only occurring in the deep layers. It may be surprising at first sight that the different spectral models give rather similar results, considering that the cutoffs range from 20 to 700 hours and the variance contained in them ranges from 14 to $750 \mathrm{~cm}^{2} / \mathrm{s}^{2}$. The reason is, of course, that the timescale of the lowfrequency spectral cutoffs is too long to contribute significantly on the 1- to 5-hour scale relevant for the Pegasus profiles.

The asymptotic value of about $1-2 \mathrm{~cm} / \mathrm{s}$ for the observed deep rms differences in Figure 3 has a number of reasons. First, this curve is not expected to go to zero since some profiles as deep as $4500 \mathrm{~m}$ are included which thus have a $1 / 2$ hour lag at $4000 \mathrm{~m}$. Second, there are inherent errors of the instrument, resulting from imperfect positioning, as well as instrument motion that does not follow the horizontal flow. The positioning and thus the flow measurement can have a bias due to errors in the transponder depths (order $5 \mathrm{~m}$ ) and separations (order $10 \mathrm{~m}$ ), acoustic distance calculations (order $3 \mathrm{~m}$ ) and Pegasus depth measurements (order $10 \mathrm{~m}$ ). Using the estimates in parentheses for the accuracy of the respective parameters, the induced systematic velocity errors are each of the order of a few millimeters per second (U. Send et al. (submitted manuscript, 1994) give simple approximate formulas for this). Thus the total navigational error could be of order $1 \mathrm{~cm} / \mathrm{s}$.

Allowing for this background level then, there is reason- able agreement of the $400-\mathrm{m}$ averages up to about $1000 \mathrm{~m}$. Above that depth, the raw differences still follow the prediction, while a distinct departure of the $400-\mathrm{m}$ averages is visible. This is consistent with ideas about the dominant vertical scales of internal waves, at least from midlatitudes. The GM75 vertical wavenumber distribution suggests that most $(50 \%)$ of the energy is contained in mode numbers less than $6,90 \%$ in mode numbers less than 12 . This was tested by calculating many realizations of synthetic horizontal current profiles using a large number of modal constituents with amplitudes according to GM75 and random phases. Visual inspection of these confirmed that the dominant vertical scales were contained in modes $1-12$. This corresponds to wavelengths of $220 \mathrm{~m}$ (mode 12) to $440 \mathrm{~m}$ (mode 6) at the GM75 reference value of $N=3 \mathrm{cph}$. Pinkel et al.'s [1987] direct observations of (midlatitude) current profile time series are in good agreement with this, where vertical scales of $300-500 \mathrm{~m}$ were found $(200 \mathrm{~m}$ in the near-inertial band). He also noted that the internal tide had vertical wavelengths that were much longer (though the vertical coherence scale for the tides was only about twice the size of the continuum value, i.e., about $150 \mathrm{~m}$ (R. Pinkel, personal communication, 1993)). The internal tides will be shown below to have appreciable amplitudes as well.

Since the local vertical wavelength scales as $N^{-1 / 2}$ and $N$ takes 3-4 times the GM75 reference value in the upper $500 \mathrm{~m}$ of our data set, vertical scales can be expected to be 1-2 times smaller there than the $400-\mathrm{m}$ averaging scale chosen for the dashed curves. Farther below the scale would be larger. Therefore the $400-\mathrm{m}$ averages formed would reduce (only) the upper layer down/up differences somewhat, which is consistent with the behavior in Figure 3. One might question the validity of applying above midlatitude scaling and observations of the vertical scales near the equator. In support of this, our own equatorial XBT data from the M14 and M16 cruises (not shown here) also exhibit vertical displacements in phase over $200-500 \mathrm{~m}$. As a further test, equatorial current meter moorings (discussed below) were used to extract many realizations of the horizontal current profiles spaced 2-4 hours apart. Some typical profiles that showed appreciable differences at 4 hours lag are presented in Figure 4. These differences shown are suggestive of large vertical scales $(>400 \mathrm{~m})$ below the thermocline and smaller scales above and are qualitatively similar to the Pegasus differences shown in Figure 2. These profiles support the previous wavenumber estimates and the corresponding explanation of Figure 3.

\section{Comparison With Moored Data}

Three current meter moorings had been deployed between the two cruises in a section along $44^{\circ} \mathrm{W}$ close to the coast (see Table 2). These time series were used to estimate the structure function $F_{\mathrm{uu}}(t)$ directly from the data, both with and without the semidiurnal tidal band $(0.076-0.085 \mathrm{cph})$ for easier comparison with GM75 spectra that do not include the tidal peaks. Using (2) for a standard Pegasus cast, the resulting down/up rms velocity differences were thus estimated from this mooring structure function. For comparison, these are first plotted without the tidal band next to the three TGM results (where also the same tidal band was then removed) in Figure 5. The excellent agreement suggests that the model spectra used have the correct spectral level in the 


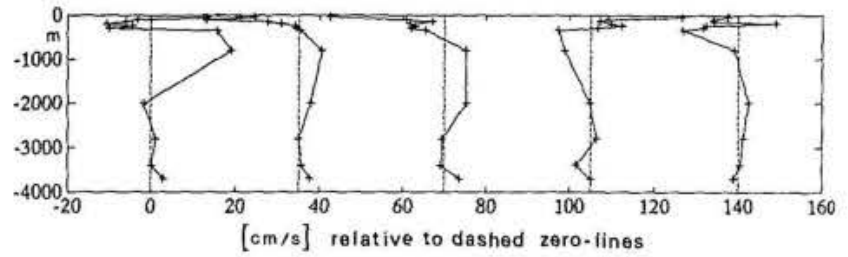

Figure 4. Four-hour differences of zonal currents from mooring K 341 , offset by $35 \mathrm{~cm} / \mathrm{s}$ each. Five samples from the first days are shown, where significant differences were present. The typical structures observed in plots like these look similar to Pegasus down/up differences (Figure 2) and emphasize the large vertical scales that may be present.

relevant frequency range and that the corresponding $N$ scaling works well, even in the strong thermocline.

The comparison of the complete mooring estimates (including the tides) with the observed down/up differences is shown in Figure 6 for the mooring in the deepest water (the other ones are similar but have even stronger tides). The agreement between predicted and observed rms differences is slightly reduced now (compared to the TGM prediction, Figure 3), due to the inclusion of the tides. In fact, the tidal bands alone (circles) could explain the down/up observed differences at the location of that mooring. Since however the total rms values (crosses) are the root of the squares of tidal and nontidal bands, it turns out that mostly these bands contribute about equally. Since there is a steady decrease in tidal amplitudes from mooring K339 to K341 (moving into deeper water), it must be assumed that farther away from the coast, the tides contribute less than the internal wave continuum. If the deep-ocean internal tide had $50 \%$ or less of the K341 level, the agreement with the observed Pegasus down/up differences would be as good as in Figure 3 again.

\section{Instrument Performance}

The first objective of the study has been reached at this point. The agreement between $\mathrm{rms}$ down/up differences observed in the Pegasus profiles and predictions from theory (TGM spectrum) or from moored statistics shows that there is sufficient natural variability to explain the magnitude, depth dependence, and statistics of those differences. This does not necessarily mean that instrumental errors or other factors do not contribute significantly to the observed differences. However, from an instrumental point of view, the instrument is good enough for this kind of study since the natural variability is at least as large as instrumental errors.

These statements at first sight do not seem to apply to the deeper levels (below 2500-3000 m), since there the predictions and observations diverge somewhat. Indeed, the predicted up/down differences must go to zero at the bottom (zero time lag), while the instrument noise level remains. In

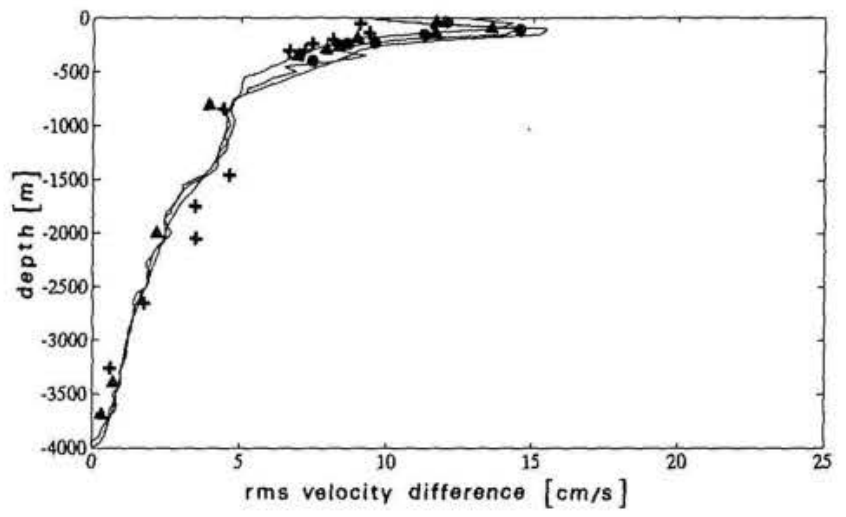

Figure 5. Predictions of up/down differences using the structure function from the TGM spectrum ( $5^{\circ}$ cutoff) and from the moored current meters, after removing the tidal band $(0.076-0.085 \mathrm{cph})$. The three curves are the spectral predictions for the average M14 and M16 buoyancy frequency profile and for a profile near the moorings. The different symbols distinguish current meters on the three moorings (circles, K339; crosses, K340; triangles, K341).

section 6 , however, it will be shown that the instantaneous error in the horizontal currents due to natural variability is $1.5-2 \mathrm{~cm} / \mathrm{s} \mathrm{rms}$ in one component, which is the same order as the filtered instrument noise.

Considering the number of approximations and simplifications that entered the above analysis, the similarity of observed and predicted down/up differences is quite surprising. It is strong evidence that the modeled variability, in particular, the internal wave spectra, can be used to make quantitative estimates of errors in current profiles (if the lower-frequency motions are sought with the observations). The total error bars for flow profiles will be larger than the curves in Figures 3-6 (which were for differences over short times), since variance from periods longer than 6 hours will generally contribute, and this is the subject of the following sections.

\section{Errors Induced in Midlatitude Profiles}

Generally, the expected rms error in a single measurement of a mean value (here the low-frequency current) is the rms value of the fluctuations (here the internal wave motions). If two values separated in time by $\Delta t$ can be averaged, as is the case for the down/up current profiles, the rms error reduces somewhat to

$$
\begin{aligned}
\langle| 0.5[\mathbf{u}(t)+\mathbf{u}(t+\Delta t)] & \left.-\left.\langle\mathbf{u}\rangle\right|^{2}\right\rangle^{1 / 2} \\
& =\left\{0.5 \operatorname{Var}_{\mathbf{u}}\left[1+\rho_{\mathrm{uu}}(\Delta t)\right]\right\}^{1 / 2}
\end{aligned}
$$

Table 2. Current Meters Used

\begin{tabular}{ccccc}
\hline Mooring & \multicolumn{1}{c}{ Deployed } & Latitude & Longitude & $\begin{array}{c}\text { Water Depth, } \\
\mathrm{m}\end{array}$ \\
\hline K339 & Oct. 12, 1990 to Sept. 8, 1991 & $00^{\circ} 04.5^{\prime} \mathrm{N}$ & $44^{\circ} 22.4^{\prime} \mathrm{W}$ & 545 \\
K340 & Oct. 12, 1990 to Sept. 8, 1991 & $00^{\circ} 25.2^{\prime} \mathrm{N}$ & $44^{\circ} 15.0^{\prime} \mathrm{W}$ & 3340 \\
K341 & Oct. 13, 1990 to Sept. 9, 1991 & $01^{\circ} 33.3^{\prime} \mathrm{N}$ & $44^{\circ} 00.7^{\prime} \mathrm{W}$ & 3997
\end{tabular}



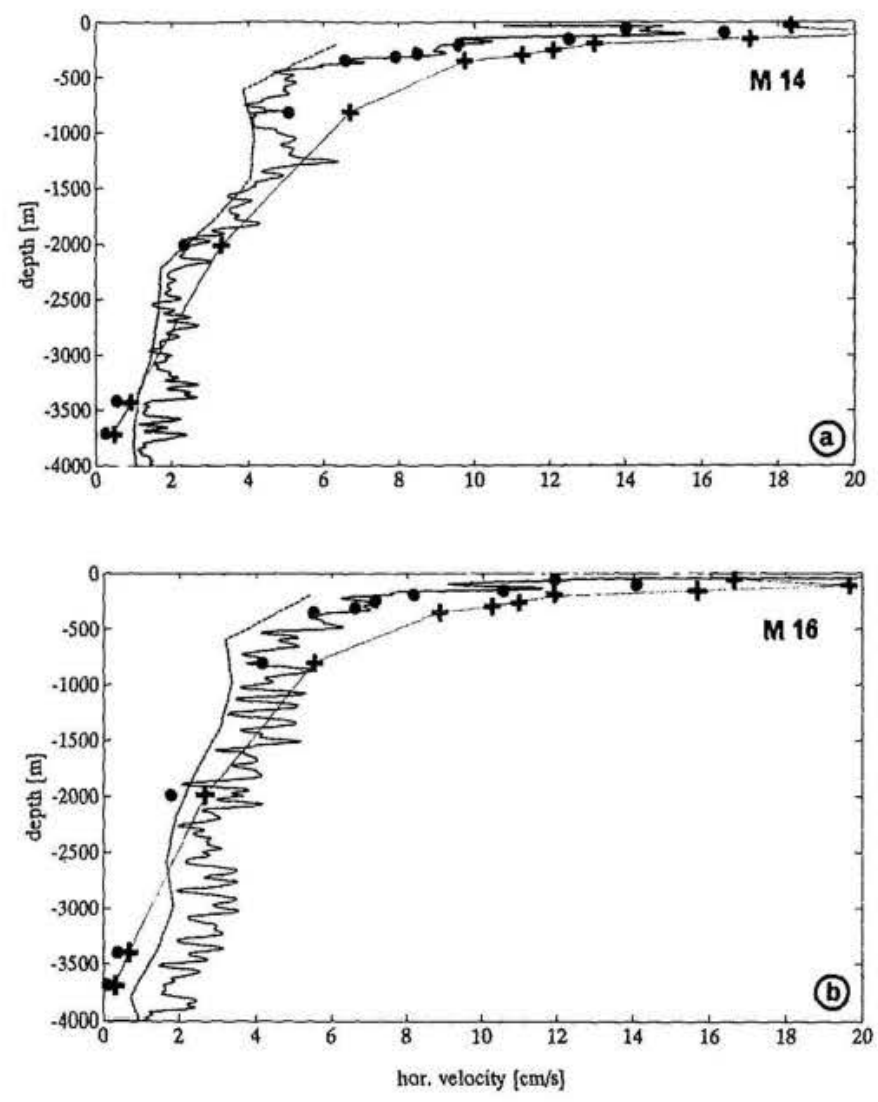

Figure 6. Observed $\mathrm{rms}$ down/up differences (solid and dashed, as in Figure 3). Predictions from deepwater mooring K341 with tides (crosses connected by dotted curve) and from tidal component only (circles). (a) M14. (b) M16.

where $\rho$ now designates the normalized covariance (correlation coefficient) function.

At sufficient distance from the equator, the expected error can immediately be given from the GM variance of

$$
\operatorname{Var}_{\mathrm{u}}=44 \frac{N}{3 \mathrm{cph}} \frac{f_{30^{\circ}}}{f} \mathrm{~cm}^{2} \mathrm{~s}^{-2}
$$

(Munk [1981], combined with the modified $f$ dependence from (3)). Using the covariance function shape for the midlatitude GM spectrum, plotted as the lower dashed line in Figure 7, relation (5) can be used to calculate the reduction in the error variance by averaging the down and up values at each depth. Approximately, the rms error is not noticeably reduced up to lags of 1 hour, at 2.5 hours it is down by $25 \%$, at $4-6$ hours the reduction is $50 \%$. The typical rms errors for down/up-averaged $\mathbf{u}$ at each depth then range from $2 \mathrm{~cm} / \mathrm{s}$ at depth $\left(N=0.3 \mathrm{cph}\right.$, lag $\left.=0, f=30^{\circ}\right)$ to $5 \mathrm{~cm} / \mathrm{s}$ in a $\mathrm{GM}$ reference thermocline $\left(N=3 \mathrm{cph}\right.$, lag $=4$ hours, $\left.f=30^{\circ}\right)$.

For given current profiles, the errors at each depth can thus be calculated from (6), with the additional use of (5) if down/up or more profiles are averaged. For error bars on profiles of current components, those vector results should be divided by $2^{1 / 2}$ but then multiplied by 2 to obtain 2 standard deviation limits $(95 \%)$.

One might try to reduce the error by piecewise vertical averages of the current profile over segments much longer
This is done implicitly if the transport in a layer is calculated. However, in section 3 it was shown that even $400-\mathrm{m}$ averages cover at most two typical vertical wavelengths (in the thermocline). This will reduce the rms error at most by $2^{1 / 2}$ (and probably less if even longer-scale internal tides are present). Thus to within this factor, the error estimates from (6) and (5) are valid even for typical vertical layer averages. Note that the relevant length again is not given by the vertical coherence scale but by the dominant vertical wavenumber, since the averaging is done on individual profiles.

\section{Errors Induced in Tropical Profiles}

In the tropics, the spectral shape is not as well established, and in view of the wide range of variances resulting from the three TGM shapes (cutoffs) considered above, some more careful evaluation of equatorial spectra is required.

For equatorial situations, the truncated GM frequency spectrum was shown above to provide a very robust description of the high-frequency spectral level and shape, even in regions of large stratification and high shear. It was capable of quantifying the down/up differences in current profiles with sufficient accuracy which suggests its use as a tool to predict the magnitude of those differences. For estimating the total error in the velocity measurements themselves, the low-frequency cutoff still needs to be suitably specified however, to approximately reproduce the actual variances.

The spectral shapes at the equator may be estimated from the three moorings used above. Figure 8 a shows the $U$ and $V$ spectra from $50 \mathrm{~m}$ depth to the bottom for all moorings, while in Figure $8 \mathrm{~b}$ the same have been scaled by $N$. The reduction in variance spread is more than one order of magnitude, and the remaining scatter is only by a factor of 3 (resulting in amplitude errors of factor $3^{1 / 2}$ ). Again, this shows that the $N$ scaling is robust.

Also shown in Figure $8 \mathrm{~b}$ is the TGM estimate, which has the same order of magnitude as the observed spectra above the semidiurnal tidal band. Below that frequency, however, there is a drop in spectral level (the higher level above the tidal band is not aliased energy from the tidal peaks). This has also been found by Wunsch and Webb [1979] and Erikson [1980] in their equatorial Indian Ocean spectra, the

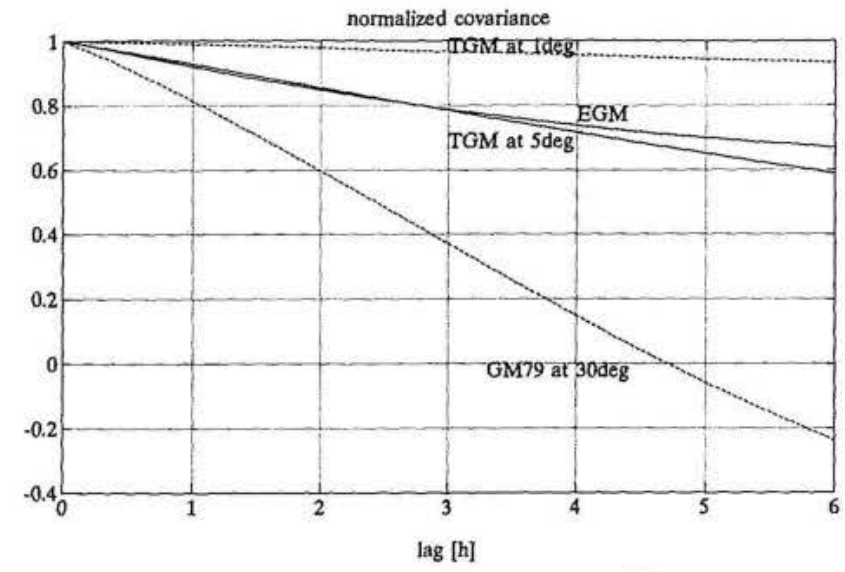

Figure 7. Normalized covariance function for midlatitude GM spectrum, for TGM with three different low-frequency cutoffs, and for EGM (integrals taken to maximum frequency 
range of which is marked in Figure 8 b. Below the tidal frequencies, the TGM spectral level is too high by about a factor of 6 , both for the Indian Ocean and our Atlantic equatorial spectra. For the approximate errors we are seeking for current profiles, we will now construct a crude equatorial frequency spectrum, which is the GM75 spectrum above the tidal bands and which continues with the same slope but with a drop of factor 6 in its level below the semidiurnal tide. This will be denoted as the "equatorial Garrett-Munk" (EGM) frequency spectrum. Taking this spectral shape to a lower frequency cutoff of $0.002 \mathrm{cph}$, which is the lower limit of periods considered in this and by Eriksen [1980], a total variance of $77 \mathrm{~cm}^{2} / \mathrm{s}^{2}$ results. This is the error variance scale we suggest to use at the equator, thus

$$
\operatorname{Var}_{u}=77 \frac{N}{3 \mathrm{cph}} \mathrm{cm}^{2} \mathrm{~s}^{-2}
$$

For the case of several profiles averaged together according to (5), the corresponding covariance shape for this EGM is included in Figure 7 as well. Applying this estimate to the observed current profiles, we arrive at rms velocity errors of $15 \mathrm{~cm} / \mathrm{s}$ at the maximum stratification (which is 3 times larger than the reference value of $3 \mathrm{cph}$ ), of $5 \mathrm{~cm} / \mathrm{s}$ in the middle of the water column, and of $2.5 \mathrm{~cm} / \mathrm{s}$ in the deep levels. One could now estimate the expected up/down differences from these values with the help of (1) and Figure 7, but for ease of comparison they have already been included in Figure 3 as one of the dotted curves. For single current component $95 \%$ errors, one would have to multiply by $2^{1 / 2}$ again.

This error variance can not be appreciably reduced by either forming piecewise vertical averages or by averaging the down/up profiles: The vertical scales are similar to the midlatitude case, as was suggested in section 3 by the equatorial moorings and expendable bathythermograph (XBT) data. Therefore the discussion of section 6 about vertical averages applies here as well. The down/up averages are even less effective than in the midlatitude case, since the covariance function for the EGM spectrum is rather flat on the 1-5 hour scale (see Figure 7). This is due to the low-frequency motions that contribute much of the energy now.

\section{Summary}

It has been shown that observed down/up differences in current profiles from the tropical Atlantic are in reasonable agreement with predictions from theoretical internal wave spectra and from mooring statistics. This demonstrates that the dominant errors in those instantaneous current profiles (with regard to low-frequency motions) are not of instrumental nature but are due to internal waves. Well established midlatitude models for internal wave spectra (GM75 with minor modifications) have then been used to yield estimates of the error in current profiles, as a function of buoyancy frequency $N$, latitude $(f)$, and time interval between profiles that might be averaged. For equatorial cases, the high-frequency part of the midlatitude GM spectra was still a good description, but below the semidiurnal tidal frequency, a crude match to Atlantic and Indian Ocean frequency profiles was applied. This then yielded consistent error estimates for our Pegasus profiles. This frequency spectrum
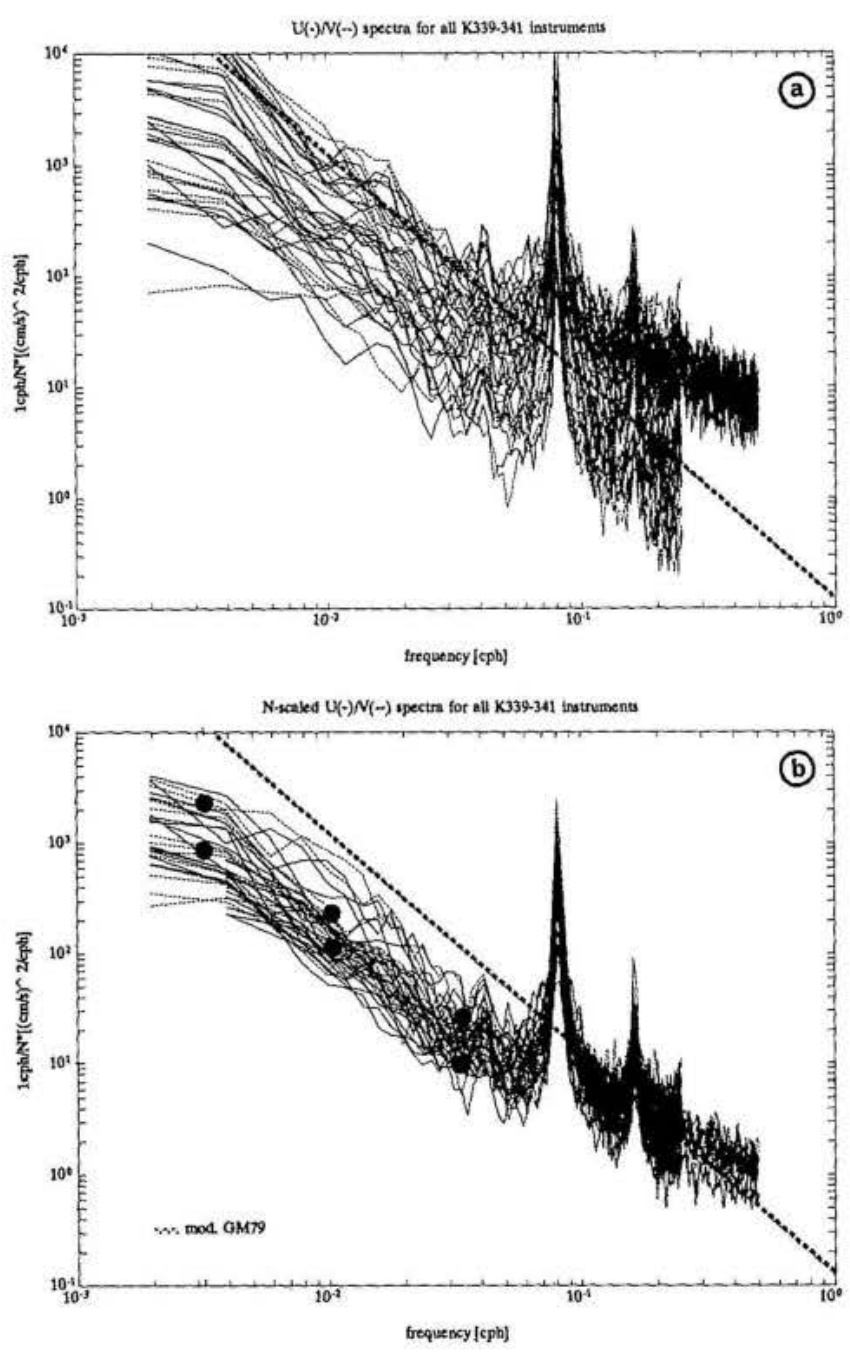

Figure 8. (a) $U$ (solid) $/ V$ (dash) energy spectra from all three moorings at depths from $50 \mathrm{~m}$ to the bottom, sampling interval was 1 or 2 hours. (b) The same but scaled with $N$. The range of values from Erikson [1980] is indicated by circles. (The raised energy level at above-tidal frequencies is not due to spectral leakage from the tidal peak. The same levels are obtained if the tidal and lower frequencies are first eliminated by filtering.)

constructed is not meant to be a new universal formulation for equatorial internal waves. Instead, we have sought the simplest description that is consistent with observations and serves our needs to estimate approximate errors, while remaining as close as possible to the successful higherfrequency and midlatitude description of the GM spectrum.

An equivalent study should be possible to estimate the internal wave induced errors in geostrophic currents and transports calculated from hydrographic data. This will be the topic of a later study.

\section{References}

Eriksen, C. C., Evidence for a continuous spectrum of equatorial waves in the Indian Ocean, J. Geophys. Res., 85(C6), 3285-3303, 1980.

Firing, E., Deep zonal currents in the central equatorial Pacific, $J$. Mar. Res., 45, 791-812, 1987.

Firing, E., and P. Hacker, ADCP results from WHP P16/17, WOCE 
Notes 4, pp. 6-12, U.S. WOCE Off., Tex. A \& M Univ., College Station 1992.

Fischer, J., and M. Visbeck, Deep velocity profiling with selfcontained ADCPs, J. Atmos. Oceanic Technol., 10(5), 764-773, 1993.

Garrett, C., and W. Munk, Space-time scales of internal waves: A progress report, J. Geophys. Res., 80(3), 291-297, 1975.

Munk, W., Internal waves and small-scale processes, in Evolution of Physical Oceanography, edited by B. A. Warren and C. Wunsch, pp. 264-291, MIT Press, Cambridge, Mass., 1981.

Pinkel, R., A. Plueddemann, and R. Williams, Internal wave observations from FLIP in MILDEX, J. Phys. Oceanogr., 17, 1737$1757,1987$.
Spain, P. F., D. L. Dorson, and H. T. Rossby, Pegasus: A simple, acoustically tracked, velocity profiler, Deep Sea Res., 28, 1553$1567,1981$.

Wunsch, C., and S. Webb, The climatology of deep ocean internal waves, J. Phys. Oceanogr., 9, 235-243, 1979.

U. Send, Institut für Meereskunde, Düsternbrooker Weg 20, 24105 Kiel, Germany. (e-mail: usend@meereskunde.uni.kiel.d400.de)

(Received April 29, 1993; revised January 24, 1994; accepted April 27, 1994.) 